
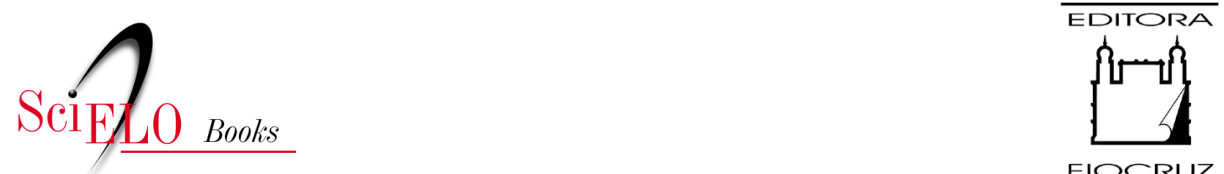

FIOCRUZ

\title{
Parte II - Combatendo Nazistas e Mosquitos Minerais para a Guerra: Os programas do rio Doce e da Mica
}

\author{
André Luiz Vieira de Campos
}

\section{SciELO Books / SciELO Livros / SciELO Libros}

CAMPOS, A. L. V. Minerais para a Guerra:

Os programas do rio Doce e da Mica. In: Políticas Internacionais de

Saúde na Era Vargas: o Serviço Especial de Saúde Pública, 1942-1960 [online]. Rio de Janeiro: Editora FIOCRUZ, 2006, pp. 173-189. História e saúde collection. ISBN: 978-65-5708-100-6.

https://doi.org/10.7476/9786557081006.0009.

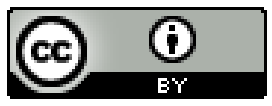

All the contents of this work, except where otherwise noted, is licensed under a Creative Commons Attribution 4.0 International license.

Todo o conteúdo deste trabalho, exceto quando houver ressalva, é publicado sob a licença Creative Commons Atribição 4.0.

Todo el contenido de esta obra, excepto donde se indique lo contrario, está bajo licencia de la licencia Creative Commons Reconocimento 4.0. 


\section{Minerais para a Guerra:}

\section{Os Programas do Río Doce e da Míca}

Segundo os Acordos de Washington, o Brasil comprometia-se a aumentar a produção de minério de ferro das minas de Itabira, em Minas Gerais, exportando-a pelo porto de Vitória, no Espírito Santo. Depósitos de ferro na Europa localizavam-se em territórios ocupados pelos nazistas, obrigando os ingleses a se valerem cada vez mais da produção brasileira. Além dos britânicos, também os americanos interessavam-se pelos minerais brasileiros. ${ }^{1}$ Disposto a suprir a demanda crescente, o governo brasileiro criou, em 1942, a Companhia Vale do Rio Doce (CVRD). Esta incorporou a estrada de ferro Vitória-Minas, o único meio de transporte entre as minas e o litoral. Para reconstruir a estrada de ferro, cuja rota atravessava o vale do Rio Doce, o governo comissionou uma companhia norteamericana que empregou cerca de seis mil trabalhadores. ${ }^{2}$ Assim como na Amazônia, a ação sanitária do Sesp no Rio Doce ajustava-se perfeitamente aos planos de state and nation building de Vargas. Se a fundação da Vale do Rio Doce - que viria a se transformar numa das maiores estatais brasileiras - e a reconstrução da estrada de ferro afinavam-se com os projetos de desenvolvimento econômico governamentais, o programa sanitário, ao fomentar a construção de uma rede de unidades de saúde, contribuía para a ampliação do "poder infra-estrutural do Estado" sobre o território nacional, com o poder público atuando em um outro 'sertão' do Brasil. ${ }^{3}$

Como no Amazonas, as doenças que assolavam o vale do Rio Doce constituíam-se em obstáculos àqueles planos econômicos. Exatamente num trecho onde a estrada de ferro precisava de maiores reparos, no alto vale do Rio Doce, um tipo bastante maligno de malária acometia a população. 
A empresa americana responsável pela reconstrução da estrada avaliou que, em virtude da malária, para cada seis empregados efetivamente trabaIhando, dez deveriam ser mantidos na folha de pagamento. O Export-Import Bank já havia sugerido a Nelson Rockefeller que organizasse um programa sanitário para o vale: "se as condições sanitárias (...) não forem melhoradas, a reconstrução da estrada de ferro será atrasada e grande parte dos trabalhadores trazidos de fora ficarão incapacitados para o trabalho" ${ }^{\prime 4}$

O Escritório preparou uma reunião no Rio de Janeiro para discutir a questão. Presentes, além do enviado do Iaia, estavam o ministro Capanema, um representante da Fundação Rockefeller e outro do Export-Import Bank. Capanema sugeriu que a Fundação Rockefeller organizasse o programa sanitário para o Rio Doce, porém seu representante declinou. A Fundação, naquele momento, já estava abandonando sua intervenção na área da saúde pública, no Brasil, para se concentrar no financiamento da educação médica e da pesquisa científica. Diante deste quadro, houve um consenso de que o Sesp se encarregaria do projeto de saneamento do vale, ${ }^{5} \mathrm{em}$ virtude do que um novo acordo seria assinado com o laia em 10 de fevereiro de 1943, com o estabelecimento do Programa do Rio Doce.

A área abrangida pelo Programa do Rio Doce era, comparando-se com a área do Programa da Amazônia, relativamente pequena - na verdade, não abrangia nem toda a região daquele vale, mas apenas o território em torno da estrada de ferro. $O$ projeto limitava-se às três maiores cidades do vale: Governador Valadares, Aimorés e Colatina, com foco nos acampamentos de trabalhadores e nas pequenas vilas espalhadas ao longo dos 600 quilômetros da estrada de ferro. ${ }^{6}$ Ainda conforme o contrato, o cuidado médico dos trabalhadores nas minas seria provido pela CVRD e não pelo Sesp. ${ }^{7}$

\section{O Saneamento dos Campos de Trabalho}

O Programa do Rio Doce dividia-se em duas frentes de ação: a primeira e mais imediata consistiu no saneamento dos acampamentos de trabalhadores espalhados pelos entornos de toda a extensão da estrada de ferro, o que incluía o controle de malária e o atendimento médico aos envolvidos na reconstrução da ferrovia. A segunda frente constava de um programa permanente de saúde pública a ser viabilizado nas vilas e cidades do vale, e implicou a construção de uma rede de unidades sanitárias, sistemas de águas e esgotos, hospitais e clínicas, além de formação profissional e educação sanitária. 
Para empreender a primeira etapa do Programa, seu diretor, o médico americano James Knott, fez um levantamento das condições dos campos de trabalho. Apesar de longo, vale a pena transcrever o documento:

O empreiteiro é responsável por construir os campos de trabalho: naturalmente ele gasta o mínimo que pode. Os homens solteiros são reunidos em grupos de 12 a 20 pessoas e alojados em barracões. As familias são reunidas em barracões similares, com compartimentos para cada uma delas. Cerca de $40 \%$ dos trabalhadores estão com as famílias. Um acampamento (...) comporta entre 100 e 300 pessoas (...) e será ocupado por 12 a 18 meses. Os trabalhadores seguem o empreiteiro a cada contrato e podem ser chamados de Brazilian Okies. Eles são analfabetos e sempre estão sem dinheiro e em dívida. Se chove e não trabalham, não recebem.

As casas são de sapê: paredes de barro e teto de folhas de palmeiras. $O$ chão é de terra batida. Os compartimentos que dividem as 'casas' individuais são apenas da altura de um muro. Fumaça e insetos podem passar de um apartamento familiar para outro. A cozinha fica num espaço úmido, serm chaminé.

Um espaço no teto é deixado para que a fumaça do fogão suba e, à noite, os mosquitos entram facilmente por este buraco. As janelas e portas das moradias são cobertas por folhas de palmeiras. Durante o dia, moscas entram e saem livremente. O interior das casas é escuro pois as janelas são pequenas e os muros estão sujos pela fumaça negra do fogareiro. As paredes de barro, logo abrem-se em frestas profundas onde insetos encontram refúgio.

O acampamento, normalmente, é construído à beira de um riacho ou pântano para facilitar o fornecimento de água, que é simplesmente bombeada de lá. Não há banheiros. Durante o dia, as pessoas fazem suas necessidades no mato, porém, à noite, eles mal se afastam da entrada da casa. Certamente os riachos são poluídos. As mulheres, na falta de tanques, lavam as roupas diretamente nos rios, ficando dentro da água todo o tempo, expostas à contaminação de doenças. Os pântanos são, naturalmente, focos de anofelinos e, se alguém chegar no campo com malária, toda a população arrisca-se a ser infectada.

Na medida em que estas pessoas não criam raízes, elas não têm o hábito de cultivar hortas. Sua dieta consiste d e feijão, arroz, mandioca, açúcar, café, milho, pão, carne de porco, carne seca, bananas, batata doce e abóbora. Tudo é comprado na venda do empreiteiro sob forma de 
crédito. Leite para as crianças é impossivel de se obter. As crianças são as que mais sofrem nestes acampamentos. Sua dieta é deficiente e elas estão constantemente expostas a disenterias e infecções intestinais. Estas doenças, ao lado da pobreza da alimentação, são a maior causa da alta taxa de mortalidade infantil nestes acampamentos. ${ }^{8}$

Diante de todo o exposto, o Sesp condicionou a construção dos campos de trabalhadores a requisitos mínimos, entre os quais: a escolha de lugar salubre para os acampamentos; uma casa com quintal para que cada família pudesse cultivar uma horta; as casas deveriam ter latrinas e proteção contra mosquitos; e um reservatório de água livre de contaminação em cada campo. ${ }^{9}$ Os empreiteiros responderam que "estavam dispostos" a seguir as instruções sanitárias do Sesp. "desde que isto não aumentasse seus custos", e sugestionaram que a CVRD arcasse com as despesas decorrentes das exigências. ${ }^{10}$

Entretanto, apesar do apoio do diretor-médico e de outros funcionários graduados da CVRD, a direção da empresa não acatou a sugestão dos empreiteiros.$^{11} \mathrm{O}$ resultado foi um impasse, o que obrigou o Sesp a buscar a adesão ao Programa negociando diretamente com cada empreiteiro. ${ }^{12}$ James Knott, diante da intransigência destes, avaliou que se os empreiteiros "tivessem que pagar um salário de quatro dólares por dia, chova ou faça sol, teríamos um outro quadro. Neste caso, seria economicamente interessante proteger a saúde dos trabalhadores para aumentar sua produtividade." 13

O Programa do Rio Doce enfrentou, pois, um desafio incial: o Sesp teve que negociar e convencer cada empreiteiro, além da CVRD, a adotar seus procedimentos sanitários nos campos de trabalho. Não temos informações sobre se todos aderiram aos pressupostos sanitários, porém segundo os dirigentes da agência os primeiros resultados positivos do trabalho começaram a aparecer já no início de 1944, quando o Sesp conseguiu determinar o lugar de 18 campos de trabalho - drenados e livres de focos de mosquitos -, além de construir casas com privadas e pequenos reservatórios de água. ${ }^{14} \mathrm{Em} \mathrm{1945}$, o Sesp organizou os primeiros cursos para formação de inspetores sanitários com as tarefas de "ensinar a população dos campos a usar os equipamentos" e fornecer educação sanitária para as famílias. ${ }^{15}$

A avaliação dos resultados feita pelos documentos oficiais é bastante otimista. O relatório anual da CVRD do ano de 1949 registrou que, entre 1942 e 1949 , a produção das minas de Itabira crescera 1.425\%: o vale do Rio Doce, "saneado pelo esforço do Sesp e pelas melhorias empreendidas 
pela CVRD, pode ser considerado, hoje, como uma das regiões de maior desenvolvimento em nosso país". ${ }^{16}$

\section{O Controle de Malária}

A malária se fazia presente em grande parte dos estados do Espírito Santo e Minas Gerais; e mesmo Vitória, a capital do Espírito Santo, não estava livre da doença. ${ }^{17}$ Quando o Projeto Rio Doce começou suas operaçōes, um surto de malária assaltava Governador Valadares, Minas Gerais. A epidemia começara em dezembro do ano anterior e, em janeiro de 1943, havia assumido proporções alarmantes. Uma inusitada temporada de chuvas ainda colaborou ainda mais para propiciar condições ótimas para o surto epidêmico.

Entretanto, tal como observamos para o Amazonas, o meio ambiente não se configurava no único responsável pela epidemia de malária em Governador Valadares: o maior foco de anofelinos da região havia sido produzido por atividade humana. Para completar o quadro epidêmico, houvera um intenso fluxo de migrantes atraídos pelas oportunidades de trabalho proporcionadas pelos investimentos na reconstrução da estrada de ferro. Os recém-chegados, com certeza, tiveram um importante papel no processo epidêmico, pois desde 1938 não se registrava na cidade um surto daquela magnitude. A epidemia atacou todos os bairros da cidade, com ainda pior sorte para os distritos mais pobres. Na cidade havia apenas uma farmácia, onde tabletes de atebrina eram vendidos a dois cruzeiros, um preço que poucos podiam pagar, considerando que a média do salário na região era de cinco cruzeiros por dia.

Em março de 1943, após uma intervenção do Sesp, a epidemia estava sob controle (Penido et al., 1948). ${ }^{18}$ Tal como no vale amazônico, também o Rio Doce foi objeto de investigação epidemiológica e entomológica. O Sesp fez um levantamento em 50 localidades, disposto a obter informações sobre a distribuição da malária (Penido, 1947). ${ }^{19}$ As pesquisas indicaram que nem todas as regiões do vale estavam infectadas pelo impaludismo: a doença se apresentava no alto e no baixo cursos da estrada de ferro - o médio curso da estrada, cobrindo os 200 quilômetros que iam de Colatina até a vila de Derribadinha e seguindo o curso do rio Doce, estava, portanto, livre de malária. ${ }^{20} \mathrm{O}$ baixo curso da estrada de ferro, situado entre Colatina e Vitória, era uma região malarígena com graus variáveis de intensidade. A rota mais alta da estrada de ferro, já no estado de Minas 
Gerais, entre Derribadinha e Desembargador Drummond - uma área que incluía a cidade de Governador Valadares -, era o território mais malarígeno. Outra região livre encontrava-se ao sudoeste de Governador Valadares, entre esta cidade e Itabira, onde estavam as minas de ferro (Penido, 1947). ${ }^{21}$

O médio curso da estrada de ferro, apesar de livre de malária na década de 1940, fora castigado pela doença no início do século XX. Engenheiros que trabalharam na construção da estrada na década de 1910 deixaram relatos sobre os prejuízos que as epidemias provocavam, ao atacar os campos dos trabalhadores e vilas. ${ }^{22}$ Já em 1922, os membros de uma expedição científica que por lá passaram não encontraram nenhuma evidência do paludismo. A explicação para o desaparecimento da doença parece estar nas mudanças no meio ambiente, efeito da colonização da área. O médio curso do vale é muito estreito e já estava completamente desmatado na década de 1920. Pântanos e outros focos de reprodução de anofelinos, que na década de 1910 ainda existiam, haviam desaparecido na década seguinte e, junto com eles, a malária (Penido, 1947).

As pesquisas entomológicas conduzidas pelo Sesp ajuizaram que darlingi, albitarsis e aquasalis eram os três vetores no vale, sendo o darlingi o único transmissor no alto rio Doce, em que um posto de saúde especializado no estudo do darlingi foi estabelecido, na vila de Naque. ${ }^{23} \mathrm{Na}$ parte baixa da estrada de ferro, a transmissão de malária adquirira outras características: os pesquisadores do Sesp descobriram que o albitarsis e o aquasalis eram os principais vetores nessa região, apesar de o darlingi também ser lá encontrado. O Anopheles albitarsis achava-se limitado entre os contornos da cidade de Vitória, onde o terreno era particularmente recortado e pantanoso (Penido, 1947; Braga et al., 1948).

$O$ vale do rio Doce foi partilhado entre duas divisões administrativas: a divisão de Colatina, responsável pela parte baixa, e a de Governador Valadares, gestora da parte alta do vale (Braga et al., 1948). Na divisão de Colatina, onde a malária era menos severa e onde se concentrava a maior parte do trabalho de reconstrução da ferrovia, o controle da doença fixouse no saneamento dos acampamentos de trabalhadores (Braga et al., 1948). O Sesp distribuiu atebrina, estabeleceu postos de saúde, drenou áreas pantanosas e, após 1946, iniciou o uso de DDT nos campos, vilas e vagões de trens. ${ }^{24}$ A distribuição de atebrina era supervisionada de uma forma impensável no Amazonas: "o guarda encarregado da distribuição do medicamento obrigava os trabalhadores a engolir o tablete na sua frenter.25 
Na divisão de Governador Valadares, onde a malária atacava de maneira muito mais impiedosa, a estratégia do Sesp abrangeu não apenas os acampamentos de operários, mas também os núcleos de população do alto vale. As pesquisas sentenciaram que a transmissão da doença variava de acordo com duas bem marcadas temporadas: a estação da seca, quando o darlingi sobrevivia em seus focos residuais; e a estação chuvosa, quando o mosquito se disseminava para além desses focos (Penido, 1947).

Como o Anopheles darlingi requeria focos bem definidos de reprodução, que se reduziam durante a estação das secas, o Sesp decidiu erradicar esse mosquito do alto vale usando a estratégia bem-sucedida contra o gambiae no Nordeste brasileiro (Braga et al, 1948). Para isto, a divisão de Governador Valadares foi esquadrinhada em zonas e, em cada uma, os focos de reprodução foram numerados. Em seguida, procedeu-se a coletas para deteç̧ão de larvas do darlingi. Identificado um foco positivo, este era eliminado por meio de drenagem, aterro ou aspersão de verde-paris. Para assegurar que o foco não fosse reinfectado, inspeções periódicas eram realizadas. Após 1946, com o uso do DDT em regióes menos povoadas do vale, o darlingi foi erradicado (Penido et al., 1948; Braga et al., 1948), numa esperiência de erradicação que certamente contribuiu para fortalecer os partidários deste conceito, naquele momento.

O Programa do Rio Doce lançou também as bases de uma infraestrutura sanitária de longo prazo, sendo sua direção e operação assumida por brasileiros. Em setembro de 1944, o médico Ernani Braga tornou-se diretor do Programa e, dos seus 763 subordinados, 756 eram brasileiros. Além das medidas emergenciais já apontadas, logo o Programa iniciou a construção de centros e postos de saúde, laboratórios, clínicas e hospitais, redes de abastecimento de águas e esgotos, além de latrinas e privadas nas casas das vilas. Em setembro de 1944, funcionavam três centros de saúde (Colatina, Governador Valadares e Aimorés) e 19 postos, espalhados pelo alto e baixo vale do rio Doce, além de equipamentos urbanos para o fornecimento de águas e esgotos (ver Mapas 3 e 4). ${ }^{26}$ Para suprir de mão-de-obra as unidades, promoveram-se cursos de formação de enfermeiras, guardas sanitários, laboratoristas e visitadoras. 


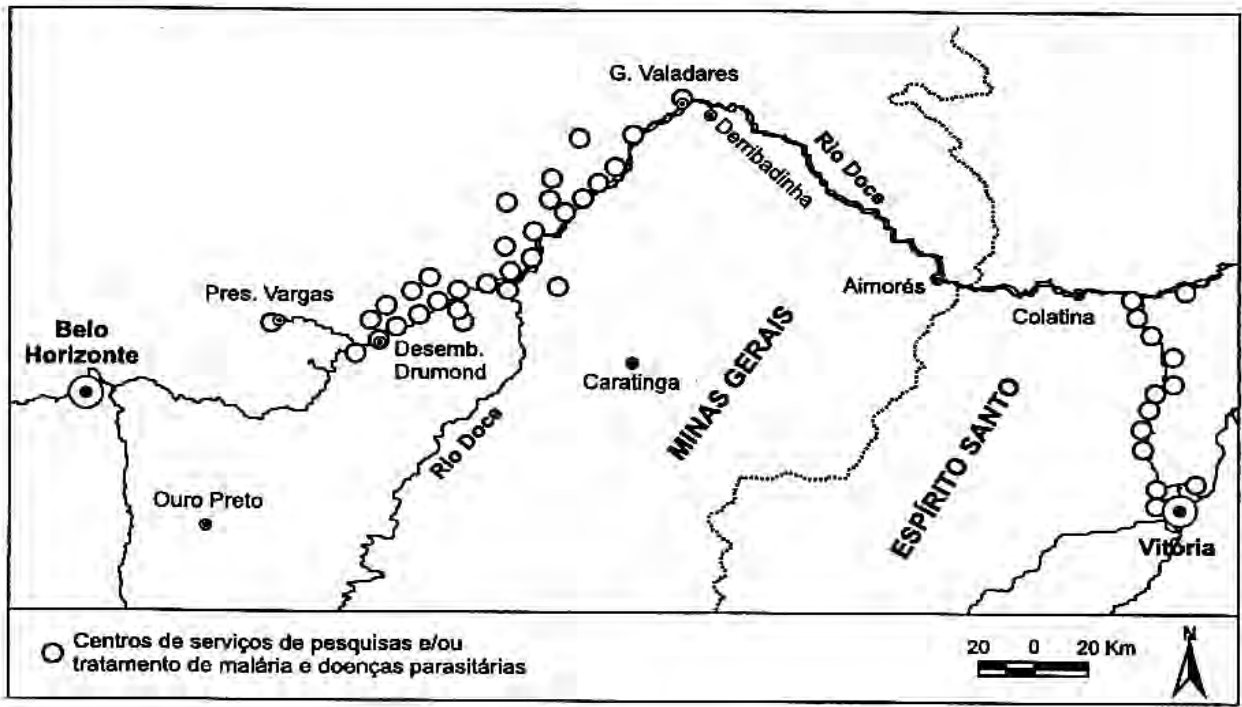

Digitalização: Rafael Chaves.

Adaptado de: Health and Sanitation Division. Newsletter, n. 39 (march 1944).

Mapa 4 - Sesp - Serviços de engenharia sanitária. Vale do Rio Doce (1943)

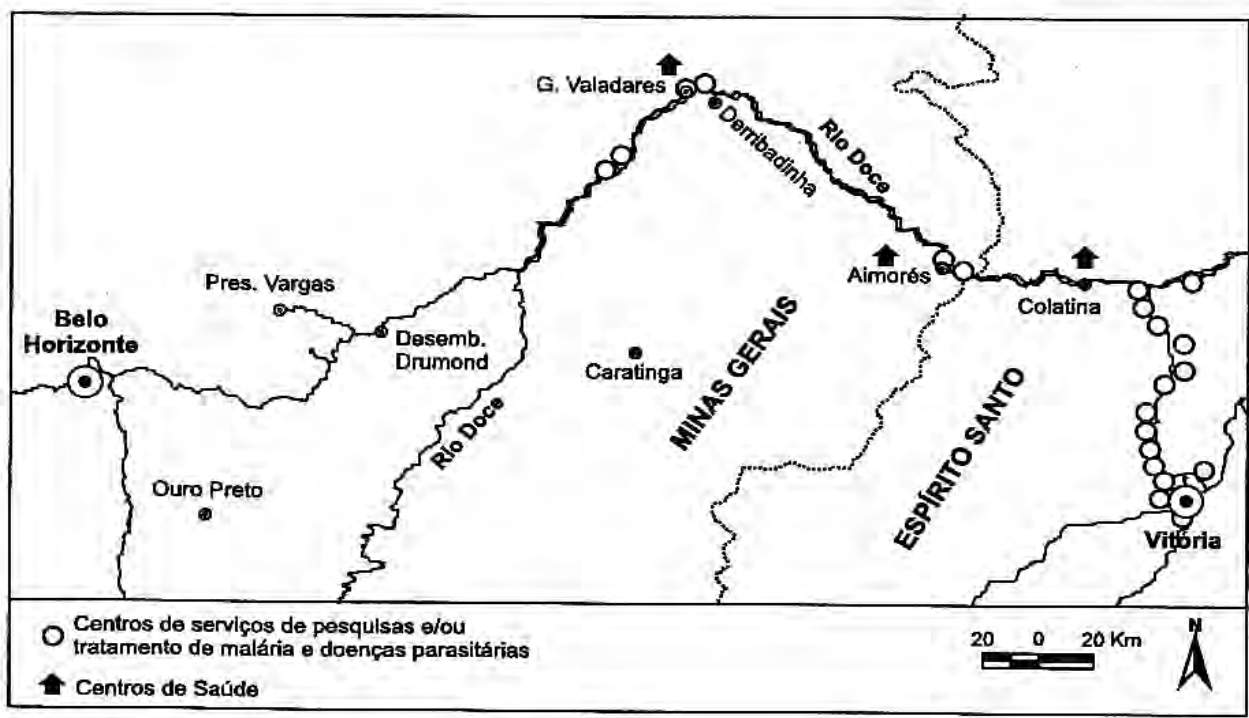

Digitalização: Rafael Chaves.

Adaptado de: Health and Sanitation Division. Newsletter, n. 39 (march 1944). 


\section{O Programa da Mica}

A Guerra também provocou um aumento na procura por dois outros minerais encontrados no Brasil; a mica e o quartzo, utilizados, principalmente, em radares e rádios. A procura por mica cresceu em 1943, em parte porque os ingleses não foram capazes de manter o nível de sua produção na Índia e o governo dos Estados Unidos contratou a compra de toda a exportação daquele mineral no Brasil. ${ }^{27}$ O Programa da Mica originou-se numa conferência do Office of Economic Warfare, em Washington, quando Rockefeller foi informado da necessidade do aumento da produção do mineral. O coordenador do Escritório instruiu o representante do Iaia no Brasil para que "todos os esforços médicos na região da produção de mica fossem encaminhados". ${ }^{28} \mathrm{Em}$ seguida, o Sesp instituiu, em outubro daquele ano, o Programa da Mica, com o objetivo de fornecer atenção médica às áreas de produção em Minas Gerais. Em janeiro de 1945 o programa foi ampliado e atingiu as regiões produtoras de quartzo no estado de Goiás. ${ }^{29}$

As minas de mica localizavam-se no vale do Rio Doce, com a produção centralizada em quatro distritos, sendo Governador Valadares o mais importante ${ }^{30}$ A produção das minas tinha uma duração muito efêmera: como observou Eugene Payne, geralmente uma lavra era explorada por apenas um ou dois anos e não era incomum se fechar uma mina "quase da noite para o dia se a qualidade do mineral não fosse satisfatória". ${ }^{31}$ Por causa deste caráter transitório, investiam o mínimo possível tanto os donos de minas quanto os financiadores do programa do Sesp. Este foi encerrado assim que a demanda, de guerra declinou. ${ }^{32}$

Outra característica da mineração de mica residia no caráter transiente da força de trabalho. Freqüentemente os trabalhadores desertavam para outras regiões, em busca de melhores condições de vida e trabalho ou fugindo de epidemias. ${ }^{33}$ Dois membros da Missão Cooke assim descreveram as relaçốes de trabalho prevalentes no setor:

os concessionários (...) que exercem monopólio sobre certas áreas, contratam trabalhadores por um salário insignificante, que mal dá para suas despesas de alimentação e outros suprimentos, os quais são comprados em vendas operadas pelos mesmos concessionários". ${ }^{34}$

Tratava-se, aqui também, de uma relação de trabalho semelhante ao sistema de barracão dos seringais da amazônia. Entretanto, era muito mais fácil, no vale do rio Doce, escapar deste esquema do que no Amazonas: os relatos dão conta de constantes fugas de trabalhadores. A descrição 
anterior retrata a situação numa mina de quartzo, mas é muito provável que nas minas de mica a realidade do trabalho fosse similar. Um funcionário do Iaia descreveu os donos das minas de mica como "comerciantes trapaceiros", cuja lógica era a de pagar "os menores salários e fazer o mínimo possível pelos trabalhadores". ${ }^{35}$

O Programa da Mica propôs-se a enfrentar desafios numa região assolada por "quase todas as doenças existentes no Brasil", sendo malária a mais prevalecente. ${ }^{36}$ A primeira investigação sanitária nas minas acontecera entre abril e maio de 1943, sob responsabilidade dos médicos Henrique Penido e Eugene Payne, este último diretor do Programa. Viajando por um território ainda inexplorado, eles classificaram como doenças recorrentes a sífilis, a febre tifóide, a úlcera tropical, a ancilostomíase, a bouba, a malária e uma grande quantidade de doenças nutricionais, especialmente o béri-béri. Por seus debilitantes efeitos na força de trabalho, a malária foi considerada a doença mais importante da região $e$, em conseqüência, o alvo principal do Programa. Os médicos relatam que, de cada quatro minas de um distrito, três "estavam praticamente fechadas e a quarta prestes a fechar, em virtude de uma febre epidêmica, aparentemente malária, que causava fuga de trabalhadores". ${ }^{37} \mathrm{Em}$ algumas minas, como no caso de Perdido, norte de Governador Valadares, a abstenção de trabalhadores alcançava quase $100 \%$. Ao lado da malária, epidemias de tifóide e varíola também atacavam a área, daí que a primeira intervenção do Sesp tenha sido a vacinação de todos os trabalhadores. ${ }^{38}$

Quando o Sesp estendeu o Programa da Mica para o estado de Goiás, abrangendo as áreas de produção de quartzco, enviou Eugene Payne numa viagem de reconhecimento sanitário que revelou que, apesar da ausência de casos de malária em Anápolis e Goiânia, as duas principais cidades de Goiás, a doença era endêmica no município de Peixe, um dos centros de produção de quartzo. ${ }^{39}$ A nosologia de Peixe incluía também febre tifóide, doença de Chagas e ancilostomíase, além de doenças respiratórias e venéreas. ${ }^{40} \mathrm{Na}$ cidade de Cristalina, outro centro de produção de quartzo, Payne não encontrou o paludismo, mas registrou febre amarela, tifóide e uma doença conhecida popularmente como 'cholerina', além de um "tipo de febre chamada localmente de febre de lama". O médico não conseguiu precisar qual a doença que os locais chamavam de 'cholerina', mas a considerou de "grave importância", porque suas vítimas em grande maioria eram crianças. Quanto à febre de lama, Payne avaliou que pudesse ser febre ondulante ou brucelose. ${ }^{41}$ 
Os meios de transporte representavam um sério problema para as políticas sanitárias do Sesp nas áreas de mineração de quartzo e mica. Um médico registrou que a região da mica era "quase inacessível", sendo que raramente alguma mina era alcançada por estrada e muitas outras estavam localizadas "entre dois a cinco dias de viagem de mula" de uma estrada principal, ${ }^{42}$ A dificuldade de transporte era tão grande que uma das propostas da Missão Cooke, em 1942, foi o uso de planadores e aviões de carga para transportar mica diretamente para os Estados Unidos, ${ }^{43} \mathrm{Em}$ 1943, quando a demanda por mica e quartzo cresceu, "aviōes de carga voavam [dos Estados Unidos] diretamente para Governador Valadares" ${ }^{44}$ 0 acesso à região ainda ficava mais difícil durante a estação chuvosa, quando grande parte dos alimentos lá produzidos deterioravam-se por falta de transporte. ${ }^{45}$

Em virtude do Programa da Mica ter um caráter explicitamente emergencial, não chegou a ser considerado um programa do Sesp, mas um "projeto especial do Iaia" administrado pelo Sesp. O Programa da Mica não obteve financiamento do Escritório e tampouco do Sesp, e sim do Federal Economic Administration, um orgão do governo americano. ${ }^{46}$ Uma outra característica deste Programa, que o diferencia de outros do Sesp, foi sua ênfase em assistência médica: seu foco estava no tratamento emergencial de trabalhadores, no sentido de garantir a continuidade da produção. Não houve a preocupação de firmar as bases de uma estrutura sanitária permanente, como se deu nos programas do Amazonas e do Rio Doce.

Eugene Payne, ao enfatizar a necessidade de atendimento médico, avaliou que seria capaz de melhorar as condições de saúde dos operários se o Sesp empregasse seis médicos-ambulantes para percorrer a região "providos de mulas, equipamentos e drogas". O diretor do Programa também sugeria que, em cada mina, "um enfermeiro do sexo masculino seria capaz de conduzir as orientações do médico e providenciar atendimento de emergência". O mesmo sentimento expressava John Seddon, quando afirmou que "tentar construir um programa adequado para esta área seria proibitivo do ponto de vista econômico e muito difícil de ser mantido em virturde da falta de transportes e meios de comunicação". Seddon concordava com Payne, no entendimento de que a "coisa mais prática a fazer" seria organizar um serviço médico focalizado nas doenças mais importantes que pudessem ser prevenidas - com vacinas, por exemplo - e providenciar tratamento médico emergencial quando fosse viável. ${ }^{47}$ 
Este direcionamento do Programa da Mica fez com que seu diretor determinasse que a assistência médica aos trabalhadores seria fornecida unicamente em função do volume de produção de cada lavra. Em Teófilo Otoni, a produção de quartzo foi considerada "muito baixa" para merecer qualquer tipo de assistência médica. ${ }^{48}$ Decisão diferente tomou-se no município de Peixe, Goiás, onde uma grande mina de quartzo foi descoberta em 1941. Na ocasião, o Sesp designou para lá um médico que operava um programa de assistência itinerante, "seguindo as minas que estão sendo abertas pelas grandes corporações". ${ }^{49}$ Usualmente, organizava-se um posto médico a cada abertura de uma mina produtiva, como em Coqueiro, Minas Gerais, que, pela sua grande produtividade, mereceu a "instalação de um subposto". ${ }^{50}$

Se considerarmos apenas os objetivos econômicos, podemos considerar o Programa da Mica um sucesso. Houve crescimento de $50 \%$ da força de trabalho empregada nas minas e registrou-se uma diminuição do absenteísmo que, em seis meses, caiu de 30\% para $13 \% .{ }^{51}$ O melhor exemplo do Programa foi a mina de Perdido, localizada numa área muito malárica e com uma alta taxa de absenteísmo. Em 1942, apenas oito pessoas lá trabalhavam; já em junho de 1944, o quantitativo era de 200 operários e a produção só fazia crescer. ${ }^{52}$

Os programas do Rio Doce e da Mica lograram êxitos diversos nos termos de um programa de saúde pública de longo prazo. O Programa da Mica teve um caráter imediatista: foi desmobilizado com o final da Guerra e não lançou bases para nenhuma infra-estrutura sanitária. Já no vale do Rio Doce, o controle de malária não só contribuiu para o incremento da produção de minério como também gerou resultados de longo prazo, pois além de auxiliar na incorporação econômica daquele território à economia nacional, estabeleceu as bases da infra-estrutura sanitária em pequenas e médias cidades do vale.

Foi no vale do Rio Doce que o Sesp experimentou um modelo de gestão de sistemas de águas e esgotos que viria a se tornar modelo nas décadas seguintes. Primeiramente, os sistemas de tratamento de águas em Colatina e Baixo Guandu (ES) e Governador Valadares, Aimorés e Conselheiro Pena (MG) foram construídos pelo Sesp e transferidos para a municipalidade, que, entretanto, não conseguiu manter o sistema, mesmo com a assessoria do Sesp. Posteriormente, encontrou-se uma alternativa, com a definição de autarquias municipais - uma estrutura jurídica mais flexível, com autonomia financeira e administrativa - denominadas 
Serviços de Administração de Águas e Esgotos (Saaes), sob gerência do Sesp e contando com múltiplas fontes de financiamento. ${ }^{53}$ Estes Serviços, que atingiram a marca de mais de $1.500 \mathrm{em}$ todo o território nacional, constituíram as primeiras autarquias do país, e serviram de modelo para os sistemas de saneamento formulados nas décadas de 1950 e 1960. Os Saaes de Governador Valadares, Conselheiro Pena e Baixo Guandu foram os primeiros a serem inaugurados, ainda em 1952 (Rezende \& Heller, 2002).

Neste sentido, o Programa do Rio Doce é bastante exemplar de como - Governo Vargas utilizou-se das políticas sanitárias do Sesp para o seu projeto de ampliação da autoridade do Estado e integração econômica do país. O depoimento de um ex-superintendente da FSesp confirma:

não é numa cidade grande, mas são várias cidades médias, pequenas, que você vai fazer tudo. Vai botar água, vai fazer melhorias sanitárias (...) Então o que é aquilo? É uma área de valorização econômica que o país precisa que tenha alguma coisa ali dentro. Então, quantas nós fizemos? (...) Veja os vales. O vale do Amazonas, vale do Jaguaribe, vale do Parnaiba, vale do Rio Doce. Todos os vales onde havia um interesse especial, agrícola ou mineral ou o que fosse, estava o Sesp com a estrutura de saúde. (Villas Boas, 1995, apud Fonseca, 2000: 405-406)

\section{Notas}

1 Memorandum from R. K. West to James Drumm, July 11, 1942, Nara, RG 229, General Records and Central Files, 1. Basic Economic, Country Files, Brazil, Box 83; "Public health activities in the Rio Doce Valley, September 1942 to September 1944", Health and Sanitation Division Newsletter, n. 64 (February 1945): 1; "Valley of the Rio Doce", Health and Sanitation Division Newsletter, n. 137 (July and August): 1.

2 "O aproveitamento das riquezas do vale do Rio Doce", Boletim do Sesp, n. 17 (Dezembro 1944): 3; "Public health activities in the Rio Doce Valley, September 1942 to September 1944", Health and Sanitation Division Newsletter, n. 64 (February 1945): I.

3 Este argumento se inspira nas conclusões de Elisa Reis (1990). A autora se utiliza do conceito de poder infra-estrutural, de Michael Mann (in The Sources of Social Power, vol. I: A History of Power from the Begginings to 1760 A. D., Cambridge: Cambridge University Press), para pensar a expansão da autoridade pública no Brasil durante a República Velha. Segundo Mann, o poder infra-estrutural refere-se à capacidade do Estado de penetrạr no território e efetivamente implementar suas decisões na sociedade civil.

4 Memorandum from R. K. West to James Drumm, July 11, 1942, Nara, RG 229, General Records and Central Files, 1. Basic Economic, Country Files, Brazil, Box 83.

5 Memorandum from the Brazilian Division to the Coordinator, July 15, 1942, Nara, RG 229, General Records, Central Files, 1. Badic Economy, Country Files, Brazil, Box 83. 
Silva, O. J. "Rio Doce Project, General comments by the medical director", p. 1. In "Report of the Brazilian field party for the month of January, 1943". Nara, RG 229. Records of the Department of Basic Economy, Health and Sanitation Division, Montly Progress Reports of Field Parties (E-143), Brazil, Box 1599,

7 "O aproveitamento das riquezas do vale do Rio Doce", Boletim do Sesp, n. 17 (Dezembro 1944): 3 .

8 Knott, J. L. "Master program for the Rio Doce Project", p. 1, 4-7, attached to "Report of the Brazilian field party for the month of January, 1943", Nara, RG 229, Records of the Department of Basic Economy, Health and Sanitation Division, Montly Progress Reports of Field Parties (E-143), Brazil, Box 1599.

- "Type of house approved by the Serviço Especial de Saúde Pública for use in laborers camps", attached to "Report for the Brazilian field party for December, 1942", Nara, RG 229, General Records, 1. Basic Economic, Country Files, Brazil, Box 83.

J. L. Knott to B. M. Krug, p. 2, January, 12, 1943, attached to "Report for the Brazilian field party for December, 1942", Nara, RG 229. General Records, 1. Basic Economic, Country Files, Brazil, Box 83.

11 "Report for the Brazilian field party for the month of November, 1943", p. 53, Nara, RG 229, Records of the Department of Basic Economy, Health and Sanitation Division, Monthly Progress Reports of Field Parties (E-143), Brazil, Box 1600.

12 "Report for the Brazilian field party for July, 1943", p. 34, Nara, RG 229, Records of Department of Basic Economy, Health and Sanitation Division, Montly Progress Report of Field Parties (E-143), Brazil, Box 1600.

13 Knott, J. L. "Master program for the Rio Doce Project", p. 8, attached to "Report of the Brazilian field party for the month of January, 1943", Nara, RG 229, Records of the Department of Basic Economy, Health and Sanitation Division, Montly Progress Reports of Field Parties (E-143), Brazil, Box 1599.

14 Cleary, E. J. "Way down the Rio Doce Vale: os trabalhos de saúde e saneamento", Boletim do Sesp, n. 8 (março 1944): 4; "The Health and Sanitation Division reports on its Rio Doce Program". Health and Sanitation Division Newsletter, , n, 64 (February 1945): 9.

15 "Completion agreement of project RD-LAB-22". August 25, 1947, AHFSSP, Série Assistência Médico-Sanitária, Pasta 30, Caixa 21.

16. Demerval, J. P. et al. "Relatório da Companhia Vale do Rio Doce, S/A para 1949", p. 2 , 18 de abril de 1950, appended to dispatch $n .972$ from the U. S. Embassy to the Department of State, June 20, 1950, Nara, RG 59, Decimal File, 1950-54, Box 4656.

i) U.S. Naval Observer at Vitória, "Malaria existent in all of Espírito Santo", 1, October 29, 1943, Nara, RG 165, General and Special Staffs, Military Intelligence Division Regional Files, 1922-44, Brazil, 2400, Box 210.

is Silva, O. J. da. "Report of the Brazilian field party for the month of Jamuary, 1943", p.1-5, Nara, RG 229, Records of the Department of Basic Economy, Health and Sanitation Division, Montly Progress Reports of Field Parties (E-143), Brazil, Box 1599: "Brazil: Rio Doce Project", Health and Sanitation Division Newsletter, n. 21 (July 1943): 6-7.

19 "Medical Report of the Rio Doce Project", p.2, Iiaa, Division of Health and Sanitation, Report for May, 1943. 
"Report for the Brazilian field party for the month of November, 1943", p, 60, Nara, RG 229, Records of the Department of Basic Economy, Health and Sanitation Division, Monthly Progress Reports of Field Parties (E-143), Brazil, Box 1600.

21 "Summary of diary of Dr. Knott, describing journey from Rio to Vitória via Belo Horizonte, Itabira, and down the Rio Doce Valley", p. 1, attached to "Report for the Brazilian field party for December, 1942". Nara, RG.229, General Records, 1. Basic Economic, Country Files, Brazil, Box 83.

22 "Medical activities - Rio Doce Project", p. 3. In "Report for the month of January", 1944, Nara, RG 229, Records of the Department of Basic Economy, Health and Sanitation Division, Monthly Progress Report of Field Parties (E-143), Brazil, Box 1601.

23 "Rio Doce Valley Project", Health and Sanitation Division Newsletter, n, 25 (September 1943): 6; "Rio Doce Project", Health and Sanitation Division Newsletter, n. 30 (November 1943): 4 ,

24 "Rio Doce Project", Health and Sanitation Division Newsletter, n. 30 (November 1943): 9; "Public health activities in the Rio Doce Valley, September 1942 to September 1944", Health and Sanitation Division Newsletter, n. 64 (February 1945); 2; "Rio Doce", Boletim do Sesp, n, 16 (novembro 1944): 10; "O programa do Rio Doce no primeiro trimestre", Boletim do Sesp, n. 12 (julho 1944): 5.

15 "Report for the Brazilian field party for the month of November, 1943", p. 63, Nara, RG 229. Records of the Department of Basic Economy, Health and Sanitation Division, Monthly Progress Reports of Field Parties (E-143), Brazil, Box 1600.

26 "Public health in the Rio Doce valley, september 1942 to 1944". Health and Sanitation Division Newsletter, n, 64 (February 1945): 2

27 "O aproveitamento das riquezas do vale do Rio Doce", Boletím do Sesp, n. 17 (Dezembro 1944): 4 ; "Report on the survey made by Dr. John W. Seddon on the mica mining region in the Governador Valadares area", p. 1, attached on "Report for the Brazilian field party for July, 1943", Nara, RG 229, Records of Department of Basic Economy, Health and Sanitation Division, Montly Progress Report of Field Parties (E-143), Brazil, Box 1600; Coordinator of Interamerican Affairs, Basic Data on the Other Republics. Washington, D. C., GPO, 1945.

Rockefeller to Christopherson, September 17, 1943, Nara, RG 229, General Records, Central Files 1. Basic Economy, Country Files, Brazil, Box 83.

Christopherson, E. H. "Health and Sanitation Program in Brazil", p. 6, April 11, 1945, Nara, RG 229, Records of the Department of Basic Economy, Health and Sanitation Division, Monthly Progress Reports of Field Parties (E-143), Brazil, Box 1601. Payne, E. H. "Na região da mica", Boletim do Sesp, n. 14 (agosto 1944): 5.

"Report on the survey made by Dr. John W. Seddon on the mica mining region in the Governador Valadares area", p. 1, attached on "Report for the Brazilian field party for July, 1943". Nara, RG 229, Records of Department of Basic Economy, Health and Sanitation Division, Montly Progress Report of Field Parties (E-143), Brazil, Box 1600; Payne, E. H. "Na região da mica", Boletim do Sesp, n. 14 (agosto 1944): 5.

32 Christopherson, E. H. "Health and Sanitation Program in Brazil", p. 6, April 11, 1945, Nara, RG 229, Records of the Department of Basic Economy, Health and Sanitation Division, Monthly Progress Reports of Field Parties (E-143), Brazil, Box 1601; O. K. D. 
Ringwood and Olive Holmes, "Status of Brazilian - U. S. War Agreements", attached to Foreign Policies Report.

"Report on the survey made by Dr. John W. Seddon on the mica mining region in the Governador Valadares area", p. 1, attached on "Report for the Brazilian field party for July, 1943", Nara, RG 229, Records of Department of Basic Economy, Health and Sanitation Division, Montly Progress Report of Field Parties (E-143), Brazil, Box 1600; "Report on health inspection trip to the mica mines north and west of Governador Valadares", p. 2, attached to "Brazilian field party report for June, 1943", Nara RG 229. Records of Department of Basic Economy, Health and Sanitation Division, Monthly Progress Report of Field Parties (E-143), Brazil, Box 1600.

Jarnes M. Boyle and Márcio de Mello Franco to Morris L. Cooke, p. 3-4. October 23, 1942, FDR Library, Morris Cooke Papers (1936-1945), M.L.C. as chief of U. S. Technical Mission to Brazil, 1942, Box 283.

"Report on the survey made by Dr. John W. Seddon on the mica mining region in the Governador Valadares area", p. 2, attached on "Report for the Brazilian field party for July, 1943", Nara, RG 229, Records of Department of Basic Economy, Health and Sanitation Division, Montly Progress Report of Field Parties (E-143), Brazil, Box 1600.

"Report on health inspection trip to the mica mines north and west of Governador Valadares", p. 1-2, attached to "Brazilian field party report for June, 1943", Nara RG 229. Records of Department of Basic Economy, Health and Sanitation Division, Monthly Progress Report of Field Parties (E-143), Brazil, Box 1600.

"O aproveitamento das riquezas do vale do Rio Doce", Boletim do Sesp, n. 17 (Dezembro 1944): 4; Payne, E. H. "Na região da mica", Boletim do Sesp, n. 14 (agosto 1944): 5.

Payne, E. H. "Crystal mining regions of Goiaz medical problems", p. 3, appended to dispatch n. 137 from the U. S. embassy to the Department of State, Rio de Janeiro February 7, 1945, Nara, RG 59, Decimal File, 1944-49, Box 5438.

Sanches, A. "Viajando pelo interior de Goiás", Boletim do Sesp, n. 20 (março 1945): 4-5. Payne, E. H. "Crystal mining regions of Goiaz medical problems", p. 2-3, appended to dispatch n. 137 from the U. S. embassy to the Department of State, Rio de Janeiro February 7, 1945, Nara, RG 59, Decimal File, 1944-49, Box 5438.

"Report on the survey made by Dr. John W. Seddon on the mica mining region in the Governador Valadares area", p. 1, attached on "Report for the Brazilian field party for July, 1943", Nara, RG 229, Records of Department of Basic Economy, Health and Sanitation Division, Montly Progress Report of Field Parties (E-143), Brazil, Box 1600. 1942. Boyle and Márcio de Mello Franco to Morris L. Cooke, p. 4-5. October 23, 1942, FDR Library, Morris Cooke Papers (1936-1945), M.L.C. as chief of U. S. Technical Mission to Brazil, 1942, Box 283.

Institute of Inter-American Affairs, Brazilian quartz goes to war, $35 \mathrm{~mm}, 17 \mathrm{~min}$, Ciaa, 1943, filmstrip, Nara, RG 229. Accession 3274; "Valley of Rio Doce", Health and Sanitation Division Newsletter, n. 137 (July and August 1950): 1.

Berle to the Secretary of State, Rio de Janeiro, July 25, 1945, FDR Library, Berle Papers, Ambassador to Brazil, 1945-46, Correspondence A-C, Box 74.

46 John D. Yagley to Einor H. Christopherson, December 8, 1943, Nara, RG 229, General Records, Central Files, 1940-45, 1. Basic Economic, Country Files, Brazil, Box 83; 
"Health and sanitation program in the mica mining areas in Brazil", appended to cover letter from William T. Thurman to Oitis E. Mulliken, March 1, 1944, Nara, RG 59, Decimal File, 1940-44, Box 4474.

47 "Report on the survey made by Dr. John W. Seddon on the mica mining region in the Governador Valadares area", p. 2-3, attached on "Report for the Brazilian field party for July, 1943", Nara, RG 229, Records of Department of Basic Economy, Health and Sanitation Division, Montly Progress Report of Field Parties (E-143), Brazil, Box 1600. Eugene Payne, "No Programa da Mica", Boletim do Sesp, n. 23 (Junho 1945): 5. Sanches, A. "Viajando pelo interior de Goiás", Boletim do Sesp, n. 20 (março 1945): 6. "Report of the Brazilian field party for June, 1944", p. 172, Nara, RG 229, Records of the Department of Basic Economy, Health and Sanitation Division, Monthly Progress Reports of Field Parties (E-143), Box 1601.

51 "Monthly report of the Brazilian field party, May, 1944", p. 35, Nara, RG 229, Records of the Department of Basic Economy, Health and Sanitation Division, Monthly Progress Reports of Field Parties (E-143), Brazil, Box 1601.

52 "O aproveitamento das riquezas do vale do Rio Doce", Boletim do Sesp, n. 17 (Dezembro 1944): 4; "Montly progress report for July, 1944", p. 131, Nara, RG 229, Records of the Department of Basic Economy, Health and Sanitation Division, Montly Progress Report of Field Parties (E-143), Brazil, Box 1601.

53 Entre as fontes, podemos citar o Bid (Rezende \& Heller, 2002). 